\title{
Probability of Error Judgment on the Superiority and Inferiority between Sire Proofs in Mixed Model Equations
}

Kenji Togashi and Kunio Yokouchi Hokkaido National Agricultural Experiment Station, Sapporo-shi 004 (Received March 7, 1988)

Key words : mixed model, sire proofs, error probability, expectation, variance

In terms of the mixed model equations, the variances of the predictors and prediction errors can be readily obtained from the elements of the generalized inverse of the coefficient matrix of the mixed model equations ${ }^{1)}$. However, even if the estimate of the one sire's genetic value is superior to that of the other sire's value, it is possible that the ranking is reverse in the true sire genetic value. So it becomes necessary to make an equation to estimate the probability of the ranking which may be reverse in the true sire genetic value contrary to the ranking in the estimates. The purpose of this paper is to devise such an equation.

\section{Error Probability}

We took up the case that estimates the sire's transmitting ability represented as the sum of the genetic group solution and the random sire solution within the genetic group $^{1,2)}$.

Let the following be given :

$$
\hat{p}_{i k}=\hat{g}_{i}+\hat{s}_{i k} \text { and } \hat{p}_{j l}=\hat{g}_{j}+\hat{s}_{j l} \text {; }
$$

$\hat{p}_{i k(j l)}$ is the $k(l)^{t h}$ sire proof within the $i(j)^{t h}$ genetic group. $\hat{g}_{i(j)}$ is the fixed

effect common to the $i(j)^{t h}$ genetic group and $\hat{s}_{i k(j l)}$ is the random effect of the $k(l)^{t h}$ sire within the $i(j)^{t h}$ genetic group.

Then, with normality, $E\left(s_{i k} \mid \hat{s}_{i k}\right)=\hat{s}_{i k}$, so these true values are shown as follows.

$$
\begin{gathered}
p_{i k}=g_{i}+s_{i k}=g_{i}+\hat{s}_{i k}+d_{i k}, \\
p_{j l}=g_{j}+s_{j l}=g_{j}+\hat{s}_{j l}+d_{j l}, \\
\text { where } E\left(d_{i k}\right)=E\left(d_{j l}\right)=0, \operatorname{Cov}\left(d_{i k}, d_{j l}\right)=0, \\
\qquad V\left(d_{i k}\right)=V\left(s_{i k} \mid \hat{s}_{i k}\right)=V\left(s_{i k}\right)-V\left(\hat{s}_{i k}\right), \\
\qquad V\left(d_{j l}\right)=V\left(s_{j l} \mid \hat{s}_{j l}\right)=V\left(s_{j l}\right)-V\left(\hat{s}_{j l}\right),
\end{gathered}
$$

混合モデル式における種雄牛評価値間の優劣判断にともなう過誤の確率：富樫研治・横内图生（農林 水産省北海道農業試験場 札幌市 004) 


\section{TOGASHI and YoKOUCHI}

and it is assumed that $\hat{s}$ and $d$ are mutually uncorrelated.

Thus, expectation and variance of the difference of $p_{i k}$ from $p_{j l}$ can be written ;

$$
\begin{aligned}
E\left(p_{i k}-p_{j l}\right) & =g_{i}-g_{j}+E\left(\hat{s}_{i k}+d_{i k}-\hat{s}_{j l}-d_{j l}\right) \\
& =E\left(\hat{g}_{i}-\hat{g}_{j}+\hat{s}_{i k}-\hat{s}_{j l}\right), \\
& \text { since } g_{i}-g_{j} \text { is an estimable function }{ }^{3)} \text {, that is, } E\left(\hat{g}_{i}-\hat{g}_{j}\right)=g_{i}-g_{j} .
\end{aligned}
$$

Then the value of expectation is given as a specified one which is obtained from the solutions of the mixed model equations.

$$
\begin{aligned}
& V\left(p_{i k}-p_{j l}\right)= V\left(\hat{s}_{i k}\right)+V\left(d_{i k}\right)+V\left(\hat{s}_{j l}\right)+V\left(d_{j l}\right) \\
&-2 \operatorname{Cov}\left(\hat{s}_{i k}, \hat{s}_{j l}\right), \text { because } g_{i(j)} \text { is fixed, } \\
&= V\left(s_{i k}\right)+V\left(s_{j l}\right)-2 \operatorname{Cov}\left(\hat{s}_{i k}, \hat{s}_{j l}\right), \\
& \text { because } V\left(d_{i k}\right)=V\left(s_{i k}\right)-V\left(\hat{s}_{i k}\right) .
\end{aligned}
$$

On the other hand, $V(\boldsymbol{s})$ and $V(\hat{\boldsymbol{s}})$ are shown as follows by Henderson ${ }^{1}$.

$V(\boldsymbol{s})=\boldsymbol{G}$ and $V(\hat{\boldsymbol{s}})=G-C_{22}$, where $C_{22}$ is the sub-matrix corresponding to $\hat{\boldsymbol{s}}$ in the generalized inverse of the coefficient matrix.

Then the variance of the difference of $p_{i k}$ from $p_{j l}$ can be given by the elements of $V(\boldsymbol{s})$ and $V(\hat{\boldsymbol{s}})$. And even if the generalized inverse could not be readily obtained, the elements of $C_{22}$ could be given by the iteration procedure ${ }^{\ddagger}$.

In this following step, we represent the expectation and variance of the difference between the two true values as " $a$ " and " $b$ ", respectively. Namely " $a$ " and " $b$ " are

$$
\begin{aligned}
& a=\hat{g}_{i}-\hat{g}_{j}+\hat{s}_{i k}-\hat{s}_{j l}, \\
& b=V\left(s_{i k}\right)+V\left(s_{j l}\right)-2 \operatorname{Cov}\left(\hat{s}_{i k}, \hat{s}_{j l}\right) .
\end{aligned}
$$

Now let us consider $\hat{p}_{i k}$ to be greater than $\hat{p}_{j l}$, however, in reality, $p_{j l}$ could be greater than $p_{i k}$. Even if we decided that $\hat{p}_{i k}$ was greater than $\hat{p}_{j l}$, it is possible that $p_{j l}$ is greater than $p_{i k}$ in the true sire genetic value. So we represent this possibility as an error probability. Then, on the basis of the normality, the error probability $(P r)$ can be shown as ;

$$
\operatorname{Pr}=1 / \sqrt{2 \pi b} \int_{-\infty}^{c} e^{-\frac{(y-a)^{2}}{2 b}} d y=1 / \sqrt{2 \pi} \int_{-\infty}^{-\frac{a}{\sqrt{b}}} e^{-y^{2} / 2} d y .
$$

In the case of sire proofs being shown as only sire solutions, " $a$ " equals the difference of $\hat{s}_{i k}$ from $\hat{s}_{j l}$ and " $b$ " actually equals the value obtained from sire proofs which are expressed as the sum of the sire solution and the genetic group solution.

\section{Example}

Suppose that we have data on progeny of related sires as given by HENDERSON ${ }^{1)}$ in appendix $\mathrm{E}$. We assume that sire 1, 2 and 3 belong to the genetic group 1, and sire 4 , 5,6 and 7 belong to the genetic group 2. Namely we represent $\hat{s}_{1}, \hat{s}_{2}, \hat{s}_{3}, \hat{s}_{4}, \hat{s}_{5}, \hat{s}_{6}$ and $\hat{s}_{7}$ as $\hat{s}_{11}, \hat{s}_{12}, \hat{s}_{13}, \hat{s}_{21}, \hat{s}_{22}, \hat{s}_{23}$ and $\hat{s}_{24}$. Also we assume that the relationships between sires in different genetic groups are zero. Suppose $\sigma^{2} s=0.392$ and $\sigma^{2} e=3.136$, and let us take the solution for $\hat{g}_{1}=0$. We should note that $E\left(\hat{g}_{i}-\hat{g}_{j}\right)$ is invariant to any generalized inverse.

In solving the mixed model equations, the solution is 
Erroneous Probability of Sire Proofs

$$
\left(\begin{array}{l}
\hat{g}_{1}+\hat{s}_{11} \\
\hat{g}_{1}+\hat{s}_{12} \\
\hat{g}_{1}+\hat{s}_{13}
\end{array}\right)=\left(\begin{array}{r}
-1.3191 \\
1.3824 \\
-0.7545
\end{array}\right),\left(\begin{array}{l}
\hat{g}_{2}+\hat{s}_{21} \\
\hat{g}_{2}+\hat{s}_{22} \\
\hat{g}_{2}+\hat{s}_{23} \\
\hat{g}_{2}+\hat{s}_{24}
\end{array}\right)=\left(\begin{array}{r}
1.6459 \\
0.4217 \\
-0.2316 \\
-0.4843
\end{array}\right) \text {. }
$$

In this following step, we take up the case of $\hat{g}_{2}+\hat{s}_{21}$ and $\hat{g}_{1}+\hat{s}_{12}$. Then,

$$
\begin{aligned}
& a=\hat{g}_{2}-\hat{g}_{1}+\hat{s}_{21}-\hat{s}_{12}=0.2635 \\
& b=V\left(s_{21}\right)+V\left(s_{12}\right)-2 \operatorname{Cov}\left(\hat{s}_{21}, \hat{s}_{12}\right) \\
& \quad=0.3920+0.3920-2(0-0.0009)=0.7858 \\
& \operatorname{Pr}=1 / \sqrt{2 \pi} \int_{-\infty}^{-\frac{a}{\sqrt{b}}} e^{-y^{2} / 2} d y=0.383 .
\end{aligned}
$$

The other error probabilities can be obtained similarly. The error probabilities are shown in Table 1.

Table 1. Error probabilities (\%)

\begin{tabular}{crrrrrrl}
\hline order & 2 & 3 & 4 & 5 & 6 & 7 & $\hat{g}_{i}+\hat{s}_{i j}$ \\
\hline 1 & 38.3 & 8.9 & 1.9 & 1.0 & 0.3 & 0.0 & $\hat{g}_{2}+\hat{s}_{21}=1.6459$ \\
2 & & 13.9 & 3.4 & 1.8 & 1.0 & 0.1 & $\hat{g}_{1}+\hat{s}_{12}=1.3824$ \\
3 & & & 20.1 & 13.2 & 9.2 & 2.5 & $\hat{g}_{2}+\hat{s}_{22}=0.4217$ \\
4 & & & & 37.7 & 27.8 & 11.0 & $\hat{g}_{2}+\hat{s}_{23}=-0.2316$ \\
5 & & & & & 38.0 & 17.3 & $\hat{g}_{2}+\hat{s}_{24}=-0.4843$ \\
6 & & & & & & 21.3 & $\hat{g}_{1}+\hat{s}_{13}=-0.7545$ \\
7 & & & & & & & $\hat{g}_{1}+\hat{s}_{11}=-0.3191$ \\
\hline
\end{tabular}

*: $\hat{g}_{i}$ (genetic group solution), $\hat{s}_{i j}$ (sire solution within genetic group)

\section{References}

1) Henderson, C.R., Proc. of the Anim. Breeding and Genetics Symp. in honor of Dr. J.L. Lush. 10-41. A.S.A.A. and A.D.S.A. Champaign. Illinois. 1973.

2) Thompson, R., Biometrics $35: 339-353.1979$.

3) Searle, S.R., Linear models. 180-188. John Wiley and Sons, Inc. New York. 1971.

4) Togashi, K. and H. TAkeda, Jpn. J. Zootech. Sci., 56 : 685-689. 1985. 